\title{
The influence of managerial optimism and self-regulation on learning and business growth expectations within an emerging economic context
}

\author{
Stern Neill ${ }^{1}$ (D) - Raghuvar Dutt Pathak ${ }^{2} \cdot$ Barbara A. Ribbens $^{3}$ • \\ Terry W. Noel $^{3} \cdot$ Gurmeet Singh $^{4}$
}

\begin{abstract}
This paper examines psychological and behavioral mechanisms that underlie business growth expectations by examining how managerial optimism and selfregulatory focus influence learning behaviors. To empirically examine these relationships, the study situates in a resource-constrained business context by studying managers in two Pacific Island economies. Results indicate that a positive view toward gains encourages exploratory learning in unknown situations; whereas, a less optimistic disposition and avoidance are related to exploitative learning. This finding is consequential as managerial learning that leans toward development of new insights and possibilities is associated with greater business growth expectations versus learning that adheres
\end{abstract}

\author{
Stern Neill \\ sneill@calpoly.edu \\ Raghuvar Dutt Pathak \\ pathak_r@usp.ac.fj \\ Barbara A. Ribbens \\ bribben@illinoisstate.edu \\ Terry W. Noel \\ terrynoel@illinoisstate.edu \\ Gurmeet Singh \\ singh_g@usp.ac.fj
}

1 Orfalea College of Business, California Polytechnic State University, 1 Grand Avenue, San Luis Obispo, CA 93407, USA

2 Graduate School of Business, Statham Campus, (Visitor, ANU, 2016-2017), University of the South Pacific, Suva, Fiji

3 College of Business, Illinois State University, Campus Box 5580, Normal, IL 61790-5580, USA

4 School of Management \& Public Administration, Faculty of Business \& Economics, University of the South Pacific, Suva, Fiji 
to familiar and proven ideas and alternatives. The study results have implications for both practice and theory.

Keywords Optimism · Regulatory focus · Managerial learning · Growth expectations · Pacific Island countries

In this paper, we seek to understand how optimism and self-regulatory orientation influence managers' envisioning of firm growth. Both optimism and self-regulatory orientation have been shown to be antecedents of firm performance (Hmieleski \& Baron, 2008, 2009). However, the mechanisms through which this occurs are not clearly understood. This paper supposes that personal traits affect how managers learn, which in turn influences expectations of business growth. In other words, a manager's disposition toward the future and self-regulating behavior influences how she/he learns, which ultimately impacts expectations of the firm's future performance (Hambrick, 2007; Hambrick \& Mason, 1984; Penrose, 1959).

Dispositions such as optimism/pessimism affect patterns of behavior through expectancies that the individual has of experiencing favorable future states (Carver \& Scheier, 2014). In the case of the firm, this impact may manifest as managerial expectations of future business growth. Whether a manager is inclined to realize that growth by exploring new opportunities or by extracting value from established business activities can affect firm performance in various ways depending on the environment in which the firm operates and the degree to which the manager influences strategy within the firm. For example, optimistic managers may be inclined to favor exploring new markets, technologies, and business processes (Barnard, 1938; Finkelstein, Hambrick, \& Cannella, 2009).

Another key component of behavior is self-regulation - the ability and willingness to monitor, evaluate, and alter one's own behavior (Bandura, 1991). Managers' selfregulatory tendencies may influence the degree to which they seek to achieve firm growth by focusing either on trying new strategies or staying with familiar approaches. Like optimism, a manager's proclivity toward certain self-regulatory strategies may influence firm growth expectations in various ways. For example, managers that are self-directed toward ideals and success will seek new approaches and original ideas that stimulate new possibilities for business growth, rather than tried-and-true plans with moderated outlooks.

While prior research suggests an association between managerial traits and firm performance in corporate settings (Helfat \& Peteraf, 2015; Nadkarni \& Herrmann, 2010), there are two gaps in the literature. First, the psychological mechanisms at work as managers' strategies play out are not clearly understood. Though optimism and selfregulatory orientation have been established as antecedents of firm performance, it is not yet clear what specific cognitive mechanisms are invoked. We propose that these dispositional traits influence how managers learn and that it is this learning that shapes views of the firm's future. Rather than directly impacting business performance, we examine a specific cognitive state - growth expectations — as being influenced by these variables.

Second, limited research on managerial attitudes and processes has occurred in the emerging economic context of small Pacific Island nations. Small island developing 
economies are challenged by having few natural and human resources in narrowlydefined business domains as well as by long distances from major trading routes and marketplaces (Briguglio, 1995), thus creating a less hospitable environment for business growth. The opportunity constraints of domestic firms in a developing economic context provide an important research setting, especially given that intrinsic and extrinsic limitations on firm resources would seem to limit expectations of business growth. Investigating managerial disposition and behaviors within this context should further reveal the microeconomic foundations that serve as the basis for economic growth and development (Porter, 1990).

\section{Conceptual development}

Optimism describes a tendency to hold positive views about the future (Scheier, Carver, \& Bridges, 1994) and has been linked to increased job performance and other workrelated outcomes (Youssef \& Luthans, 2007). Along with confidence, hope, and resilience, optimism is a component of positive psychological capital, which-along with human and social capital — can serve as a foundation for competitive advantage. Optimism builds positive expectancies that motivate goal pursuit and a favorable view of the future that extends beyond the self (Luthans \& Youssef, 2007). In general, optimism influences individual behavior in positive ways (Carver, Scheier, \& Segerstrom, 2010). In business contexts, optimism has been found to enhance managers' search for ways to improve performance (Papenhausen, 2010).

Optimism can also be detrimental to performance in some contexts. Among entrepreneurs, optimism affects decisions about the future (Shepherd, Williams, \& Patzelt, 2015), but as Hmieleski and Baron (2009) found, optimism can also lead to lower business performance. This effect is strengthened by past experience and industry dynamism, suggesting that business people may get locked into certain ways of thinking that no longer work. This finding is supported by research on strategic persistence. Dysfunctional persistence may result from managers' confidence in the correctness of current strategies stemming from higher satisfaction with previous performance. This in turn may be associated with less seeking of information from critics (Audia, Locke, \& Smith, 2000).

Regulatory focus describes a process to align goals and behaviors based on two independent self-regulatory systems: promotion focus and prevention focus (Higgins, 1997, 1998). A promotion focus draws the individual toward aspirations and hopes and the attainment of positive outcomes, while a prevention focus directs the individual to avoid negative outcomes by playing it safe. Individuals who maintain a promotion focus are more eager (Crowe \& Higgins, 1997), generate more alternatives (Liberman, Molden, Idson, \& Higgins, 2001), and engage in more exploratory problem-solving that results in creative insights (Friedman \& Förster, 2001). Within group settings, the actions of managers serve as a role model with evidence that more promotion-focused leader behavior is associated with greater employee creativity ( $\mathrm{Wu}, \mathrm{McMullen}$, Neubert, \& Yi, 2008). Hmieleski and Baron (2008) discovered that for entrepreneurs operating in dynamic environments, an individual's promotion focus is positively related to business performance, while a prevention focus is related to lower performance. The authors suppose a possible cognitive mismatch might explain this 
relationship. This study of South Pacific managers offers a partial test of this explanation by examining the effect of self-regulation on individual learning behaviors, which would impact expectations of firm growth.

Optimism and behavioral self-regulation provide frameworks from which to analyze business growth expectations in managers. As Wiklund, Davidsson, and Delmar (2003) noted, managers' beliefs about the consequences of growth will shape their overall attitude toward growth. Likewise, Ahmadi, Khanagha, Berchicci, and Jansen 2017) found that managers' regulatory focus affects their willingness to experiment. In the appropriate setting, such exploratory learning can lead to higher performance (De Noni \& Apa, 2015; Hughes, Hughes, \& Morgan, 2007; Li, 2013). However, there has been little discussion of how these generalized cognitive mechanisms affect specific attitudes such as firm growth expectations. This study examines how optimism and regulatory focus relate to attitudes toward learning behavior and subsequently to expectations of business growth.

Not all learning is equal. Exploratory learning involves search, experimentation, and the pursuit of new knowledge, while exploitative learning emphasizes existing knowledge and prior experience (March, 1991). Each represents learning but along a different trajectory: exploration moves in entirely new directions whereas exploitation occurs along existing paths (Gupta, Smith, \& Shalley, 2006). In unfamiliar situations, pursuit of the novel and original allow for creation and discovery of new insights, while reliance on the known and routine allow for refinement and extension of existing knowledge (Neill, Metcalf, \& York, 2017). Scholars continue to examine how the two learning types may coexist at the organizational and/or individual levels (e.g., Birkinshaw \& Gibson, 2004; Mom, Van Den Bosch, \& Volberda, 2009; Raisch, Birkinshaw, Probst, \& Tushman, 2009); however, there is general agreement that both forms are essential. While there may be a tendency to exploit what is known, innovation and creativity more often spring from exploration of the unknown; and yet, the familiar allows for recognizing and leveraging the unknown into something new and different. In this way, the individual engages in learning by relying on both new and existing knowledge and experience with each form of learning supporting innovation and creativity.

The type of learning a manager engages in is arguably influenced by his/her expectancies for certain personal outcomes. Optimism prompts goal-directed behaviors through positive expectancies (Luthans \& Youssef, 2007). Activated goals influence behavior through mechanisms such as strategy development or learning (Locke, Shaw, Saari, \& Latham, 1981). Optimistic individuals are more likely to directly address challenges and avoid strategies that seek to ignore or avoid external demands (Nes \& Segerstrom, 2006). Thus, optimism should positively relate to learning that directly confronts uncertainty and negatively associate with learning that disengages from the problem of not knowing. Managers who are more optimistic are likely to engage in more exploratory learning and are less likely to rely on exploitative knowledge. Stated inversely, a manager with low optimism is less likely to learn based on new insights and possibilities and more likely to acquire knowledge from existing sources and procedures.

Hypothesis H1a A manager's optimism is positively related to exploratory learning. Hypothesis H1b A manager's optimism is negatively related to exploitative learning. 
Promotion focus is concerned with ensuring gain as opposed to avoiding loss, as well as avoiding errors of omission or missing what could have been done (Higgins, 1998). A promotion focus is associated with approach-related cognition and behavior as the individual is drawn toward aspirations and the attainment of positive outcomes; whereas, a prevention focus is associated with avoidance-related thoughts and actions wherein the individual evades negative outcomes and mistakes through safe and secure means. Promotion focus has been linked to creativity and the generation and implementation of novel and useful ideas (Crowe \& Higgins, 1997; Friedman \& Förster, 2001; Lanaj, Chang, \& Johnson, 2012; Neubert, Kacmar, Carlson, Chonko, \& Roberts, 2008; Tumasjan \& Braun, 2012). Prior research suggests that an employee's promotion focus is positively associated with learning (Wallace, Butts, Johnson, Stevens, \& Smith, 2016). Additionally, evidence indicates that a CEO's promotion focus is positively related to a business's pursuit of new and existing opportunities (Kammerlander, Burger, Fust, \& Fueglistaller, 2015). These studies would suggest that a promotion focus, with its emphasis on achievement and advancement, will enable both exploratory and exploitative learning.

Hypothesis H2a Promotion focus is positively related to exploratory learning. Hypothesis H2b Promotion focus is positively related to exploitative learning.

Prevention focus is concerned with avoiding loss as opposed to seeking gain, as well as avoiding errors of commission or making a mistake (Higgins, 1997). While prior research indicates a positive link between a promotion focus and innovative behavior (Lanaj et al., 2012), there is evidence, though limited, of a negative relationship between prevention focus and creativity (Haws, Dholakia, \& Bearden, 2010). Kammerlander et al. (2015) found that prevention focus is negatively related to a firm's orientation on new, but not existing, business opportunities. Similar to a defensive posture negating pursuit of new opportunities, a prevention focus will have a negative effect on individual learning of new knowledge and skills. In seeking to avoid committing errors in pursuit of goals, a prevention focus will instead encourage reliance on what is already known and routine.

Hypothesis H3a Prevention focus is negatively related to exploratory learning. Hypothesis H3b Prevention focus is positively related to exploitative learning.

Business growth expectations represent beliefs about future product-market developments. Prior research has identified differences between the growth ambitions of entrepreneurs based on individual experience, motivations, risk propensity, strategic growth intentions and perceived success factors (Gundry \& Welsch, 2001; Miner \& Raju, 2004; Morris, Miyasaki, Watters, \& Coombes, 2006; Siegel, Siegel, \& Macmillan, 1993). Evidence indicates that high-growth entrepreneurs exhibit high levels of practical, analytical and creative intelligence, which motivates entrepreneurial behavior (Baum \& Bird, 2010). While a manager's promotion of a culture of learning may positively influence business growth through such things as innovation and an opportunity focus (Morrison \& Bergin-Seers, 2002), constraining such learning to repeated exploitation of existing and recognized resources may place limits on growth by focusing too narrowly on efficiency and reproduction and choking off aspirations toward new opportunities (Piao \& Zajac, 2016). 
We predict that a tendency to engage in exploratory learning will be more conducive to high growth expectations than exploitative learning. Managers with a tendency to engage in exploration will be more likely to expect growth in new business opportunities, while managers that engage in exploitative learning will focus on learning about ways to harvest value from current product lines and business. This may even result in the manager disregarding potential opportunities which may have accelerated growth. It is important to note that managers engaged in exploitative learning would not necessarily expect business performance to decline; rather, they would simply expect profits to be restricted to current instead of new opportunities.

Hypothesis H4a Exploratory learning will be positively associated with business growth expectations.

Hypothesis H4b Exploitative learning will be negatively associated with business growth expectations.

\section{Methodology}

The data were gathered in two Pacific island nations, Fiji and Tonga. The Republic of Fiji is an archipelago of more than 330 islands with 110 of those inhabited by 915,000 residents (CIA World Factbook, 2016a). The two largest islands contain about $87 \%$ of the population. Fiji has one of the most developed economies of the Pacific Island nations due to its two largest islands which provide forest and mineral resources in addition to the ocean resources surrounding the country. Tonga is a constitutional monarchy comprising 150 islands of which only 36 are inhabited by just over 100,000 residents (CIA World Factbook, 2016b). While tourism is the main industry in both Fiji and Tonga, both countries have significant agricultural and marine industries. Fiji has some mining as well, but most manufacturing occurring in these two island nations would be considered light in nature or classified as cottage industries. Recently, more focus has been on the effects of climate change on the Pacific Islands than on entrepreneurial attitudes and mechanisms.

South Pacific Island countries confront acute economic challenges given their small size, limited natural resources, narrowly-based economies, large distances to major markets, and vulnerability to exogenous shocks (World Bank, 2012). The national culture of Fiji and Tonga would best be described as both hierarchal (ascribed roles that reinforce unequal distribution of power and resources) and embedded (reinforcement of the status quo and restraint of action that might disrupt solidarity and order) (Schwartz, 2004), which translates into firms that are comparably low in entrepreneurial values (Neill, Pathak, \& Reddy, 2009). Understanding managerial self-regulation and how it affects business growth and success is important to the stability of these vulnerable economies and thus, this study considers this contextual frame as important to understanding the results of our study.

To measure each construct, established scales were used or adapted. Measurement reliability was evaluated using exploratory factor analysis and scale item analyses. Measures were further subjected to confirmatory factor analysis. Structural equation modeling (SEM), using LISREL XIII, was used to test the hypotheses. The proposed model was assessed based on fit of the conceptual model with the observed model, 
significance of path estimates (representing the study hypotheses), and explained variance of the endogenous variables (exploratory and exploitative learning and business growth expectations). Additional tests were performed to confirm the mediating effects.

\section{Data collection}

To test the hypotheses, data were gathered in 2012 from business executives representing firms operating in Fiji and Tonga. While each island nation presents a unique demographic and regulatory context, the two countries share a common socioeconomic profile (World Bank, 2008, 2009; United Nations, 2008). The Registrar of Companies in Fiji and the Chamber of Commerce in Tonga maintain directories of registered business operations. Complete lists of businesses were collected from these agencies and random sampling was used to select a broad sample of enterprises.

The instrument was a structured survey questionnaire, which was personally administered by trained research assistants in Fiji and Tonga. In total, 198 surveys were completed (122 from Fiji and 76 from Tonga). To be included in the study, respondents had to indicate having at least a year of experience working at the firm and moderate involvement in the firm's strategic decisions (indication of four or higher on a sevenpoint scale). Given these requirements, 28 respondents were removed from the study (four for insufficient experience, 20 for insufficient strategic involvement, and four for non-response on the experience and involvement questions), leaving 170 usable responses (99 from Fiji and 71 from Tonga). The remaining informants were predominately senior- and mid-level managers (52\% senior management, $20 \%$ middle management and $28 \%$ staff) with a marketing (38\%) or operations $(47 \%)$ background and an average of 10 years of experience and high involvement in strategic decisions (average of 5.8 on a seven-point scale). The sample represented locally-owned (85\%), small and medium-sized businesses ( $92 \%$ with 100 or fewer employees), primarily from the service sector (78\%), which are comparable to the establishment profile of prior studies in these countries (Neill, Singh, \& Pathak, 2014; Singh, Pathak, \& Naz, 2010).

\section{Measurement}

Multi-item scales were used for each of the six constructs. Each measure is based on an established scale. Table 1 contains the items for this study's measures including source and content.

\section{Results}

\section{Measurement results}

Unidimensionality among scale items was first assessed using item-to-scale correlations $(>.50)$ and exploratory factor analyses with all items loading highly on a single factor ( $\geq$.70) (Hair, Black, Babin, \& Anderson, 2010). Based on this analysis, one item was removed from growth expectation and optimism. This trimmed set was further subjected to confirmatory factor analysis with all six constructs modeled as first-order 


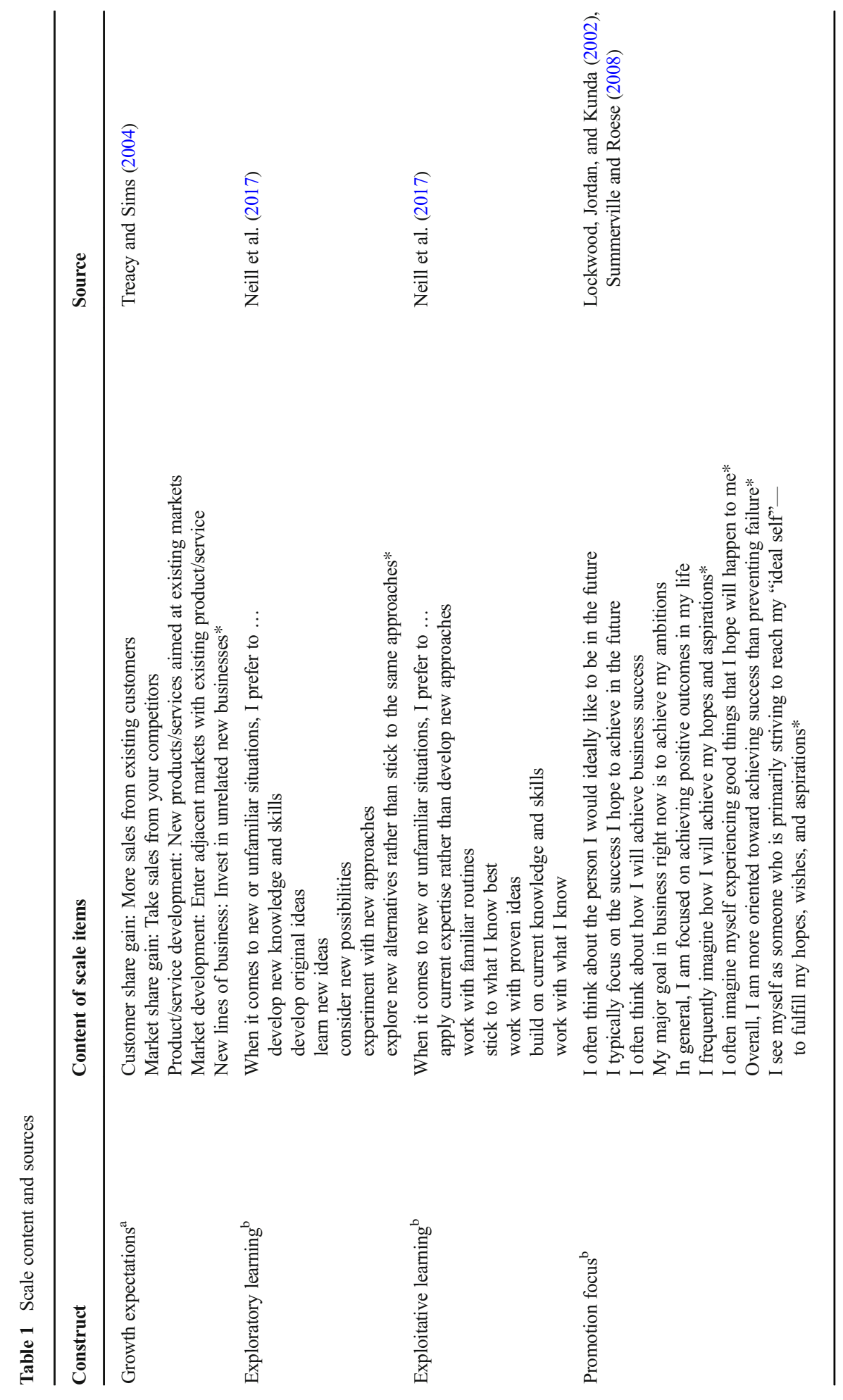




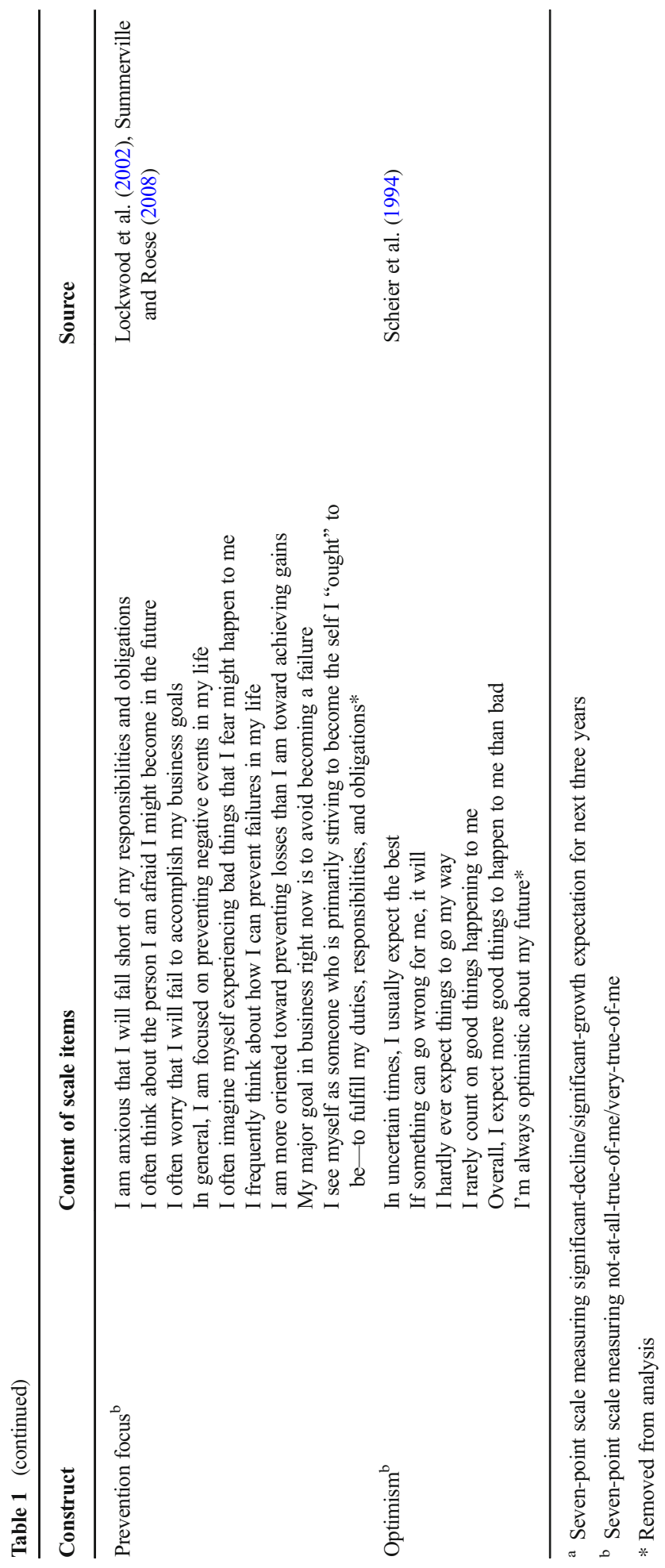


factors in LISREL 8.8 using the covariance matrix as input. Internal consistency and goodness-of-fit measures were used to assess the reliability, model fit, and discriminant validity. For internal consistency, composite reliability and average variance extracted (AVE) measures are reported. For measures of fit, absolute and incremental indices are reported (Hair et al., 2010). Chi-square $\left(\chi^{2}\right)$ indicates the degree to which the observed input matrix is predicted by the estimated model. Although $\chi^{2}$ is the only measure with an associated statistical test, relying solely on the statistic is not recommended, as it is sensitive to large sample sizes. The standardized root mean square residual (SRMR), which measures the discrepancy between the observed and estimated covariances or correlations, is another absolute indicator of model fit. The comparative fit index (CFI) is also recommended to address sample-related inconsistency. The CFI gauges the extent to which the estimated model is superior to a comparison model (e.g., the "null" model of no relationships within the data).

Examining both within- and across-factor loadings and measurement error led to the removal of six items: one from exploratory learning, four from promotion focus, and one from prevention focus. Based on this analysis, the internal consistency estimates indicated adequate support, with goodness-of-fit results indicating that the estimated measurement model adequately represented the observed input matrix $\left(\chi^{2}\right.$ $=1,067.64, d f=480 ;$ SRMR $=.09 ;$ CFI $=.92)$. To determine if each measure was empirically distinct, discriminant validity was assessed and supported in all cases, as the square of the parameter estimate $(\varphi)$ between each pair of constructs was less than the mean of the pair's AVE estimates (Fornell \& Larcker, 1981). Table 2 presents the internal consistency estimates, summary statistics, and correlations among constructs.

\section{Structural model results}

To control for measurement error, each loading estimate $(\lambda)$ was fixed as the square root of the reliability estimate, and the error term $(\theta)$ was set to one minus the reliability (Hair et al., 2010). Additionally, the number of years the manager had worked in the business was included to control for the effect of work experience on learning, and the number of employees was included to control for the effect of firm size on business growth expectations. Assuming a reliability of .80, the error term for the control

Table 2 Descriptive statistics, reliability estimates and correlation coefficients

\begin{tabular}{lrrrrrrrrr}
\hline Construct & Mean & SD & AVE & $\mathbf{1}$ & $\mathbf{2}$ & $\mathbf{3}$ & $\mathbf{4}$ & $\mathbf{5}$ & $\mathbf{6}$ \\
\hline 1 Growth expectations & 6.07 & .94 & .74 & .92 & & & & & \\
2 Exploration learning & 6.49 & .93 & .73 & $.46^{* *}$ & .93 & & & & \\
3 Exploitation learning & 6.09 & .96 & .49 & .01 & $.33^{* *}$ & .85 & & & \\
4 Promotion focus & 5.85 & .96 & .45 & $.16^{*}$ & $.41^{* *}$ & $.58^{* *}$ & .80 & & .00 \\
5 Prevention focus & 4.61 & 1.52 & .53 & $.24^{* *}$ & $.16^{*}$ & $.22^{* *}$ & $.18^{*}$ & .90 & .01 \\
6 Optimism & 4.13 & 1.69 & .60 & $.37^{* *}$ & $.22^{* *}$ & -.07 & -.01 & $.60^{* *}$ & .88 \\
7 Experience & 10.46 & 10.51 & - & .03 & .06 & $.16^{* *}$ & .10 & $-.20^{* *}$ & $-.21^{* *}$ \\
\hline
\end{tabular}

$S D$ Standard deviation; $A V E$ Average variance extracted $* p<.05 ; * * p<.01$ 
Table 3 Completely standardized path estimates

\begin{tabular}{lrr}
\hline Hypotheses: Path & Estimate & $t$-value \\
\hline H1a: Optimism $\rightarrow$ Exploration learning & .40 & 3.41 \\
H1b: Optimism $\rightarrow$ Exploitation learning & -.25 & -2.36 \\
H2a: Promotion focus $\rightarrow$ Exploration learning & .53 & 6.10 \\
H2b: Promotion focus $\rightarrow$ Exploitation learning & .63 & 7.93 \\
H3a: Prevention focus $\rightarrow$ Exploration learning & -.18 & -1.50 \\
H3b: Prevention focus $\rightarrow$ Exploitation learning & .31 & 2.79 \\
H4a: Exploration learning $\rightarrow$ Growth expectations & .56 & 7.23 \\
H4b: Exploitation learning $\rightarrow$ Growth expectations & -.16 & -2.01 \\
Controls & & .78 \\
Experience $\rightarrow$ Exploration learning & .07 & 1.49 \\
Experience $\rightarrow$ Exploitation learning & .12 & .80 \\
Firm size $\rightarrow$ Growth expectations & .06 & \\
\hline
\end{tabular}

$t$-values of 1.28 or greater are significant at the .10 level; $t$-values of 1.65 or greater are significant at the .05 level; $t$-values of 2.33 or greater are significant at the .01 level

measures were fixed at .20. Fixing the measurement aspect prior to estimating the structural relationships avoids the interaction of measurement and SEMs. The overall fit of the SEM was acceptable $\left(\chi^{2}=21.31, d f=7\right.$; SRMR $\left.=.05 ; \mathrm{CFI}=.95\right)$. All paths but one were statistically significant $(p<.05$ or better). Standardized path estimates are presented in Table 3. The structural equations account for 33 and $57 \%$ of the variance in exploratory and exploitative learning (respectively), and $29 \%$ of the variance in business growth expectations.

\section{Post-hoc analysis of mediating effects}

While these results suggested a good fit that supports the mediating effects of exploratory and exploitative learning, post-hoc analyses were performed to confirm the mediating function. Based on a series of steps (Hair et al., 2010), which included the addition of direct effects between the three antecedents and growth expectations, full

Table 4 Post-hoc analysis of mediating effects

Direct effect on growth expectations

\begin{tabular}{lrrrrrrr} 
Model & $\chi^{2}(d f)$ & $\Delta \chi^{2}(\Delta d f)$ & SRMR & CFI & Estimate & $t$-value & Explained variance \\
\hline Alt1: Optimism & $4.61(4)$ & $13.90(1)$ & .02 & 1.00 & .30 & 3.91 & .36 \\
Alt2: Promotion focus & $17.92(4)$ & $.59(1)$ & .06 & .94 & .11 & .70 & .30 \\
Alt3: Prevention focus & $8.52(4)$ & $9.99(1)$ & .03 & .98 & .25 & 3.30 & .35 \\
\hline
\end{tabular}

$\Delta \chi^{2}$ values of 3.84 or greater are significant at the .05 level. $t$-values of 1.65 or greater are significant at the .05 level; $t$-values of 2.33 or greater are significant at the .01 level

$A L T$ Alternative model; $d f$ Degrees of freedom; SRMR Standardized root mean square residual; CFI Comparative fit index. 
mediation effects were assessed. After first confirming that the direct, unmediated relationships were significant (see Table 2), three alternative models were estimated, one for each antecedent variable. For promotion focus $\left(\Delta \chi^{2}=.59\right)$, full mediation was confirmed as the direct effects were equal to zero, and there were no significant improvements in model fit based on chi-square difference tests $(p>.05)$. However, full mediation is not supported for optimism nor prevention focus, as the direct effects are statistically significant $(\beta=.30, p<.01$ and $\beta=.25, p<.01$, respectively), and the fit of the models significantly improves $\left(\Delta \chi^{2}=13.90, p<.01\right.$ and $\Delta \chi^{2}=9.99, p<.01$, respectively). These results are summarized in Table 4.

\section{Summary of structural model results}

Figure 1 presents a summary of the hypotheses test results. Overall, the results offer support for Hypotheses 1-4. Optimism (H1) has contrary effects on exploratory learning $(\beta=.40, p<.01)$ and exploitation $(\beta=-.25, p<.01)$, while promotion focus (H2) serves to facilitate both exploratory $(\beta=.53, p<.01)$ and exploitative $(\beta=.63$, $p<.01)$ learning. With greater prevention focus (H3), exploitative learning increases $(\beta=.31, p<.01)$; however, the effect of prevention focus on exploratory learning, while weak, is negative $(\beta=-.18, p<.10)$. The results suggest contrary effects for exploratory $(\beta=.56, p<.01)$ and exploitative $(\beta=-.16, \mathrm{p}<.05)$ learning on growth expectations - with the former positively related and the later negatively related. Work experience, as a control, does not affect exploratory learning $(\beta=.07$, $p>.10$ ), but does have a positive, though weak, effect on the use of exploitative learning $(\beta=.12, p<.10)$. As an additional control, firm size does not influence a manager's business growth expectations $(\beta=.06, p>.10)$. While a post-hoc analysis confirmed that exploratory and exploitative learning fully mediate the effect of promotion focus, the results indicate direct, positive effects for both optimism and prevention focus on growth expectations. These results, illustrated below, are discussed next along with implications.

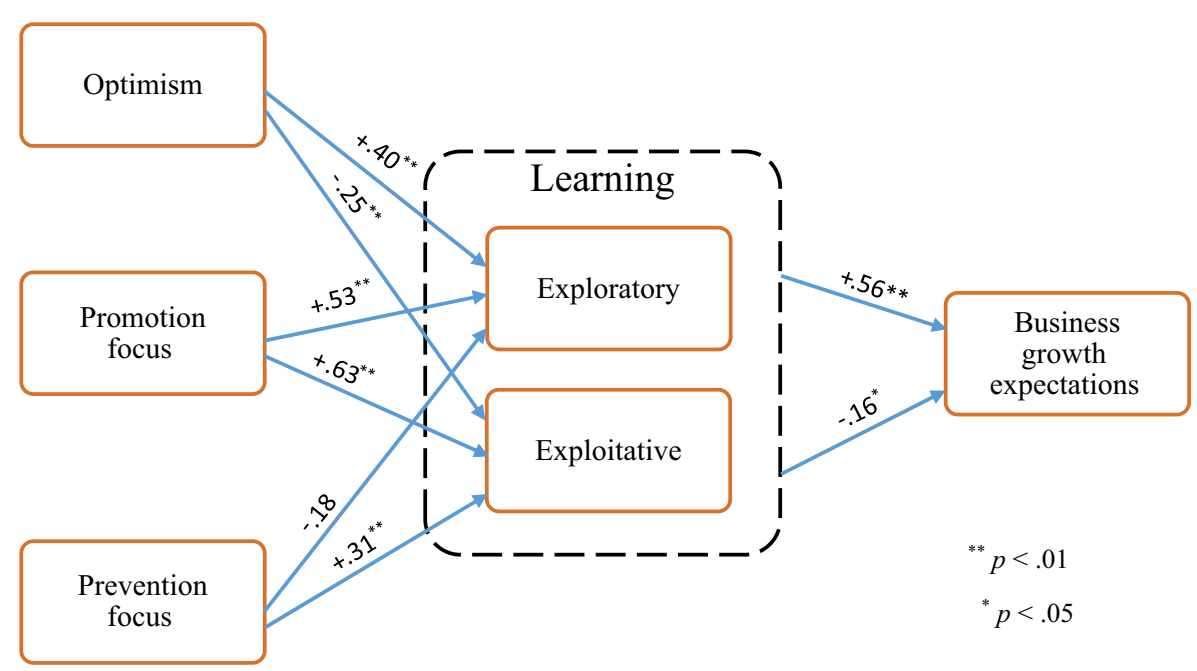

Fig. 1 Hypotheses test results: Completely standardized path estimates 


\section{Discussion}

Optimism, promotion focus, and prevention focus were examined as antecedents of firm growth expectations, mediated by learning behavior. Generalized positive expectations coupled with a cognitive regulatory focus on gain rather than loss prevention resulted in higher specific expectations of firm growth in a sample of executives from two South Pacific Island countries. These findings are consistent with previous research that disposition toward optimism and a promotion focus support managers' learning through exploring of strategies for growing a firm. However, previous studies have not directly addressed the specific cognitive mechanisms through which performance is enhanced by learning.

Our findings point to a specific set of expectations about growth that are the product of learning behaviors, which form the basis of intentions to grow and goals to make those intentions manifest. The study results are also consistent with goal setting research. For complex tasks (such as running a business), learning goals (goals that focus on generating strategies for higher performance as opposed to performance itself) lead to better outcomes than performance goals (Noel \& Latham, 2006; Winters \& Latham, 1996). To the degree that optimism and a promotion focus prompt managers to set goals for generating strategies and obtaining relevant new information, firm growth is likely to be the result.

\section{Practical implications}

Since both optimism (Carver \& Scheier, 2014) and regulatory focus (Higgins, 1998) are malleable, it is possible that managers can be trained to promote growth by adopting a more optimistic outlook coupled with a promotion focus. None of this suggests that exploiting current business processes that have high payoff is wrong. In fact, while our results suggest that optimism promotes exploratory learning in unknown business situations, it also serves to diminish reliance on existing knowledge and methods, which may not be an optimal learning strategy. The optimistic manager may over-rely on exploring new possibilities, overlooking the tried-and-true; perhaps lower optimism is needed though this might diminish the manager's outlook on business growth. Managers must decide constantly whether the value-adding processes that they have developed heretofore are likely to continue generating profits. Both promotion and prevention focus facilitate the productive use of what is already known; however, learning in unknown situations is facilitated by a promotion focus and hindered under prevention focus. Given the ever-quickening pace of change in the business environment, we would be remiss in advising managers to only do what they do now more efficiently. At some point, value-adding activities cease to add value.

Another practical consideration for managers is the influence of optimism, regulatory focus and learning on actual firm performance. While our results examine the effect of managerial traits on learning and business growth expectations, studies indicate that optimism and prevention focus may have a negative impact on business performance, especially in dynamic environments (Hmieleski \& Baron, 2008, 2009). This suggests no simple solution for managers striving for greater business growth and needing to achieve actual business success. While there is support for a relationship between learning and business growth expectations, there are important caveats to overreliance on either form 
of learning. Repetitive overreliance on exploiting current knowledge and existing alternatives discourages experimentation with new possibilities, which inhibits exploration (Piao \& Zajac, 2016); whereas, reliance on exploratory, to the exclusion of exploitative, learning may never realize full returns. Growth expectations would appear to follow exploratory learning; whereas, exploitative learning, much like exploitative business strategy, suffers from a tendency toward obsolescence through strict reliance on existing ideas, technologies and markets, which limits business growth prospects.

Finally, given our study is set in the South Pacific, the context and how the findings apply are of particular significance. The success or failure of enterprises rests in part on how executives think, behave and act. Understanding why managers develop the organizations they do is highly relevant for managers of small and medium-size enterprises, especially those operating in resource constrained environments. South Pacific managers lead firms that provide the majority of employment and whose success could enhance economic growth and generate additional capital for largescale operations (Singh, Pathak, Shee, Kazmi, \& Parker, 2013). Given these managers operate in relatively isolated economies with cultures that reinforce hierarchy and the status quo, there are few role models for innovation and limited opportunities for entrepreneurial education, which further highlights the importance of interpreting and applying our results.

\section{Limitations and future research}

This paper explores a psychological variable (growth expectations) and its antecedents. While we provide evidence that optimism and regulatory focus are linked to expectations of business success, there is clearly a large gap between thinking one will accomplish something and actually accomplishing it. Future studies may focus on the specific link between growth expectations and firm performance. We also recognize the limitations of survey data. Future work should seek objective measures of firm growth in addition to self-reports of growth expectations. Lastly, managing a company is an extraordinarily complex affair, making it near-impossible to capture all the subtle nuances in a manager's thinking and the execution of strategic initiatives. Richer and more nuanced data from the actual decision processes of managers would be helpful in that regard.

There is considerable literature examining how exploratory and exploitative learning may coexist at the organizational and/or individual levels (i.e., organizational ambidexterity); however, similar investigation on the mix of regulatory focus (high, low or mixed on both promotion and prevention) is limited to a few studies (e.g., Kammerlander et al., 2015; Markovits, 2012). Brockner, Higgins, and Low (2004) suggested that promotion focus facilitates the creative spark (unknown) while prevention focus allows for evaluation of innovative ideas based on what is known. There may be merit in continuing to explore this line of enquiry, as there is much to be learned about how and when to shift from one to the other or how each works in concert with the other. Additionally, our understanding of how a manager's regulatory focus might be influenced by internal and external cues is of particular importance, especially given its influence on the balance of exploratory and exploitative learning. For example, future research might endeavor to understand the individual and situational elements that influence the executive's dominant regulatory focus (i.e., the degree to which one focus exceeds the other). 
Additionally, the study results suggest that learning does not fully mediate the relationship between the dispositional and self-regulatory characteristics of managers and business growth expectations, with empirical evidence indicating that the effect of optimism and prevention focus may influence both learning behavior and future growth expectations. While business growth expectations are partially a product of managerial learning, other factors perform a role in an executive's outlook on business growth, which includes blind faith from a manager's optimism. Further parsing the theoretical implications of these effects deserves additional investigation and cross-validation. Research might also further examine situational contingencies that both trigger or benefit from a specific balance of promotion and prevention focus or exploratory and exploitive learning and how this mix might influence business growth expectations.

The results of this study would offer a caveat that while exploratory learning might encourage sky-is-the-limit expectations, the wisdom of exploitative learning might temper expectations about future business. The next piece of the puzzle is to examine the influence of dispositional state and self-regulation on the development and implementation of business strategy (e.g., the relationship between managerial regulatory focus and new product innovation). While prior research has linked personal traits to individual creativity and innovation, an opportunity remains to directly link selfregulatory psychological states to business strategy and growth.

\section{Conclusion}

In conclusion, managers vary in their level of optimism and self-regulatory focus, which have a direct effect on learning behavior. In new and unfamiliar situations, this manifests with optimistic and promotion-oriented managers seeking to develop new insights and approaches; whereas, managers with lower optimism and a prevention focus seek to apply current knowledge and expertise. This balance of learning behaviors is pertinent given that exploratory learning is associated with higher business growth expectations, while exploitative learning is linked to lower expectations. Finding the optimal mix of psychological and behavioral elements is essential for the outlook of the overall business. While more research is needed, examining these relationships contributes to understanding the microfoundations of prosperity.

\section{References}

Ahmadi, S., Khanagha, S., Berchicci, L., \& Jansen, J. J. P. 2017. Are managers motivated to explore in the face of a new technological change? The role of regulatory focus, fit, and complexity of decision-making. Journal of Management Studies, 54(2): 209-237.

Audia, P. G., Locke, E. A., \& Smith, G. G. 2000. The paradox of success: An archival and a laboratory study of strategic persistence following radical environmental change. Academy of Management Journal, 43(5): 837-853.

Bandura, A. 1991. Social cognitive theory of self-regulation. Organizational Behavior and Human Decision Processes, 50(2): 248-287.

Barnard, C. I. 1938. The functions of the executive. Cambridge: Harvard University Press.

Baum, J. R., \& Bird, B. J. 2010. The successful intelligence of high-growth entrepreneurs: Links to new venture growth. Organization Science, 21(2): 397-412. 
Birkinshaw, J., \& Gibson, C. 2004. Building ambidexterity into an organization. MIT Sloan Management Review, 45(4): 47-55.

Briguglio, L. 1995. Small inland developing states and their economic vulnerabilities. World Development, 23(9): 1615-1632.

Brockner, J., Higgins, E. T., \& Low, M. B. 2004. Regulatory focus theory and the entrepreneurial process. Journal of Business Venturing, 19(2): 203-220.

Carver, C. S., \& Scheier, M. F. 2014. Review: Dispositional optimism. Trends in Cognitive Sciences, 18: $293-299$.

Carver, C. S., Scheier, M. F., \& Segerstrom, S. C. 2010. Optimism. Clinical Psychology Review, 30(7): 879-889.

CIA World Factbook. 2016a. The world factbook: Fiji. https://www.cia.gov/library/publications/the-worldfactbook/geos/fj.html, Accessed May 31, 2017.

CIA World Factbook. 2016b. The world factbook: Tonga. https://www.cia.gov/library/publications/the-worldfactbook/geos/tn.html, Accessed May 31, 2017.

Crowe, E., \& Higgins, E. T. 1997. Regulatory focus and strategic inclinations: Promotion and prevention in decision-making. Organizational Behavior and Human Decision Processes, 69(2): 117-132.

De Noni, I., \& Apa, R. 2015. The moderating effect of exploitative and exploratory learning on internationalisationperformance relationship in SMEs. Journal of International Entrepreneurship, 13(2): 96-117.

Finkelstein, S., Hambrick, D. C., \& Cannella, A. A. 2009. Strategic leadership: Theory and research on executives, top management teams, and boards. New York: Oxford University Press.

Fornell, C., \& Larcker, D. F. 1981. Evaluating structural equation models with unobservable variables and measurement error. Journal of Marketing Research, 18(1): 39-50.

Friedman, R. S., \& Förster, J. 2001. The effects of promotion and prevention cues on creativity. Journal of Personality and Social Psychology, 81(6): 1001-1013.

Gundry, L. K., \& Welsch, H. P. 2001. The ambitious entrepreneur: High growth strategies of women-owned enterprises. Journal of Business Venturing, 16(5): 453-470.

Gupta, A. K., Smith, K. G., \& Shalley, C. E. 2006. The interplay between exploration and exploitation. Academy of Management Journal, 49(4): 693-706.

Hair, J. F., Black, B., Babin, B. J., \& Anderson, R. E. 2010. Multivariate data analysis. Upper Saddle River: Prentice Hall.

Hambrick, D. C. 2007. Upper echelons theory: An update. Academy of Management Review, 32(2): 334-343.

Hambrick, D. C., \& Mason, P. A. 1984. Upper echelons: The organization as a reflection of its top managers. Academy of Management Review, 9(2): 193-206.

Haws, K. L., Dholakia, U. M., \& Bearden, W. O. 2010. An assessment of chronic regulatory focus measures. Journal of Marketing Research, 47(5): 967-982.

Helfat, C. E., \& Peteraf, M. A. 2015. Managerial cognitive capabilities and the microfoundations of dynamic capabilities. Strategic Management Journal, 36(6): 831-850.

Higgins, E. T. 1997. Beyond pleasure and pain. American Psychologist, 52(12): 1280-1300.

Higgins, E. T. 1998. Promotion and prevention: Regulatory focus as a motivational principle. Advances in Experimental Social Psychology, 30: 1-46.

Hmieleski, K. M., \& Baron, R. A. 2008. Regulatory focus and new venture performance: A study of entrepreneurial opportunity exploitation under conditions of risk versus uncertainty. Strategic Entrepreneurship Journal, 2: 285-299.

Hmieleski, K. M., \& Baron, R. A. 2009. Entrepreneurs' optimism and new venture performance: A social cognitive perspective. Academy of Management Journal, 52(3): 473-488.

Hughes, M., Hughes, P., \& Morgan, R. E. 2007. Exploitative learning and entrepreneurial orientation alignment in emerging young firms: Implications for market and response performance. British Journal of Management, 18(4): 359-375.

Kammerlander, N., Burger, D., Fust, A., \& Fueglistaller, U. 2015. Exploration and exploitation in established small and medium-sized enterprises: The effect of CEOs' regulatory focus. Journal of Business Venturing, 30: 582-602.

Lanaj, K., Chang, C. H., \& Johnson, R. E. 2012. Regulatory focus and work-related outcomes: A review and meta-analysis. Psychological Bulletin, 138(5): 998-1034.

Li, C. 2013. Disentangling the effect of exploratory learning and exploitative learning in product innovation process. Canadian Journal of Administrative Sciences [Revue Canadienne Des Sciences De l'Administration], 30(2): 101-114.

Liberman, N., Molden, D. C., Idson, L. C., \& Higgins, E. T. 2001. Promotion and prevention focus on alternative hypotheses: Implications for attributional functions. Journal of Personality and Social Psychology, 80(1): 5-18.

Locke, E. A., Shaw, K. N., Saari, L. M., \& Latham, G. P. 1981. Goal setting and task performance: 19691981. Psychological Bulletin, 90: 125-152. 
Lockwood, P., Jordan, C. H., \& Kunda, Z. 2002. Motivation by positive or negative role models: Regulatory focus determines who will best inspire us. Journal of Personality and Social Psychology, 83(4): 854-864.

Luthans, F., \& Youssef, C. M. 2007. Emerging positive organizational behavior. Journal of Management, 33(3): 321-349.

March, J. G. 1991. Exploration and exploitation in organizational learning. Organization Science, 2(1): 71-87.

Markovits, Y. 2012. The development of regulatory foci characters and moderation effects on satisfaction and commitment. International Journal of Psychology and Behavioral Sciences, 2(4): 71-80.

Miner, J. B., \& Raju, N. S. 2004. Risk propensity differences between managers and entrepreneurs and between low-and high-growth entrepreneurs: A reply in a more conservative vein. Journal of Applied Psychology, 89(1): 3-13.

Mom, T. J., Van Den Bosch, F. A., \& Volberda, H. W. 2009. Understanding variation in managers' ambidexterity: Investigating direct and interaction effects of formal structural and personal coordination mechanisms. Organization Science, 20(4): 812-828.

Morris, M. H., Miyasaki, N. N., Watters, C. E., \& Coombes, S. M. 2006. The dilemma of growth: Understanding venture size choices of women entrepreneurs. Journal of Small Business Management, 44(2): 221-244.

Morrison, A., \& Bergin-Seers, S. 2002. Pro-growth small businesses: Learning "architecture". Journal of Management Development, 21(5): 388-400.

Nadkarni, S., \& Herrmann, P. 2010. CEO personality, strategic flexibility, and firm performance: The case of the Indian business process outsourcing industry. Academy of Management Journal, 53(5): 1050-1073.

Neill, S., Metcalf, L. E., \& York, J. 2017. Distinguishing entrepreneurial approaches to opportunity perception. International Journal of Entrepreneurial Behavior \& Research, 23(2): 296-316.

Neill, S., Pathak, R. D., \& Reddy, N. 2009. Marketing concept manifestations in Fiji enterprises: Confirming the link to organizational competitiveness. Journal of Global Marketing, 22(1): 43-52.

Neill, S., Singh, G., \& Pathak, R. D. 2014. Technology and marketing capabilities in a developing economic context: Assessing the resource-based view within a boundary condition. International Journal of Business and Economics, 13(1): 75-92.

Nes, L. S., \& Segerstrom, S. C. 2006. Dispositional optimism and coping: A meta-analytic review. Personality and Social Psychology Review, 10(3): 235-251.

Neubert, M. J., Kacmar, K. M., Carlson, D. S., Chonko, L. B., \& Roberts, J. A. 2008. Regulatory focus as a mediator of the influence of initiating structure and servant leadership on employee behavior. Journal of Applied Psychology, 93(6): 1220-1233.

Noel, T. W., \& Latham, G. P. 2006. The importance of learning goals versus outcome goals for entrepreneurs. International Journal of Entrepreneurship and Innovation, 7(4): 213-220.

Papenhausen, C. 2010. Managerial optimism and search. Journal of Business Research, 63: 716-720.

Penrose, E. T. 1959. The theory of the growth of the firm. New York: John Wiley \& Sons.

Piao, M., \& Zajac, E. J. 2016. How exploitation impedes and impels exploration: Theory and evidence. Strategic Management Journal, 37: 1431-1447.

Porter, M. E. 1990. The competitive advantage of nations. New York: Free Press.

Raisch, S., Birkinshaw, J., Probst, G., \& Tushman, M. L. 2009. Organizational ambidexterity: Balancing exploitation and exploration for sustained performance. Organization Science, 20(4): 685-695.

Scheier, M. F., Carver, C. S., \& Bridges, M. W. 1994. Distinguishing optimism from neuroticism (and trait anxiety, self-mastery, and self-esteem): A reevaluation of the life orientation test. Journal of Personality and Social Psychology, 67(6): 1063-1078.

Schwartz, S. H. 2004. Mapping and interpreting cultural differences around the world. In H. Vinken, J. Soeters, \& P. Ester (Eds.). Comparing cultures: Dimensions of culture in a comparative perspective: $43-$ 73. Liden: Brill.

Shepherd, D. A., Williams, T. A., \& Patzelt, H. 2015. Thinking about entrepreneurial decision making: Review and research agenda. Journal of Management, 41(1): 11-46.

Siegel, R., Siegel, E., \& Macmillan, I. C. 1993. Characteristics distinguishing high-growth ventures. Journal of Business Venturing, 8(2): 169-180.

Singh, G., Pathak, R. D., \& Naz, R. 2010. Issues faced by SMEs in the internationalization process: Results from Fiji and Samoa. International Journal of Emerging Markets, 5(2): 153-182.

Singh, S., Pathak, R. D., Shee, H., Kazmi, A., \& Parker, D. 2013. Interplay between entrepreneurial characteristics, organisational structure, corporate culture and SME performance: Empirical results from Fiji Islands. International Journal of Entrepreneurship and Small Business, 18(2): 229-246.

Summerville, A., \& Roese, N. J. 2008. Self-report measures of individual differences in regulatory focus: A cautionary note. Journal of Research in Personality, 42(1): 247-254.

Treacy, M., \& Sims, J. 2004. Take command of your growth. Harvard Business Review, 82(4): 127-133. 
Tumasjan, A., \& Braun, R. 2012. In the eye of the beholder: How regulatory focus and self-efficacy interact in influencing opportunity recognition. Journal of Business Venturing, 27(6): 622-636.

United Nations. 2008. Statistics of the human development report. http://hdr.undp.org/en/statistics/, Accessed January 17, 2009.

Wallace, J. C., Butts, M. M., Johnson, P. D., Stevens, F. G., \& Smith, M. B. 2016. A multilevel model of employee innovation: Understanding the effects of regulatory focus, thriving, and employee involvement climate. Journal of Management, 42(4): 982-1004.

Wiklund, J., Davidsson, P., \& Delmar, F. 2003. What do they think and feel about growth? An expectancyvalue approach to small business managers' attitudes toward growth. Entrepreneurship: Theory and Practice, 27(3): 247-270.

Winters, D., \& Latham, G. P. 1996. The effect of learning versus outcome goals on a simple versus a complex task. Group \& Organization Management, 21(2): 236-250.

World Bank. 2008. World bank group entrepreneurship survey 2008. http://go.worldbank.org/T8G73Z9ZM0, Accessed July 8, 2009.

World Bank. 2009. World development indicators database. http://siteresources.worldbank. org/DATASTATISTICS/Resources/GDP PPP.pdf, Accessed July 5, 2009.

World Bank. 2012. Pacific Islands overview. http://www.worldbank.org/en/country/pacificislands/overview, Accessed September 23, 2012.

Wu, C., McMullen, J. S., Neubert, M. J., \& Yi, X. 2008. The influence of leader regulatory focus on employee creativity. Journal of Business Venturing, 23(5): 587-602.

Youssef, C. M., \& Luthans, F. 2007. Positive organizational behavior in the workplace the impact of hope, optimism, and resilience. Journal of Management, 33(5): 774-800.

Stern Neill ( $\mathrm{PhD}$, Louisiana State University) is Professor of Marketing in the Orfalea College of Business at California Polytechnic State University, USA. His research includes strategic, entrepreneurial, and global marketing. He has published in the International Journal of Entrepreneurial Behavior \& Research, Entrepreneurship Research Journal, Journal of Business Research, and Industrial Marketing Management, among others.

Raghuvar Dutt Pathak (PhD, Himachal Pradesh University) is Professor of Management in the Graduate School of Business at the University of the South Pacific, Fiji. He has published three research-based books and more than 75 research papers in reputed refereed journals such as the Personality and Individual Differences, European Journal of Work and Organizational Psychology, International Journal of Project Management, Public Organization Review: A Global Journal, International Entrepreneurship and Management Journal, and Journal of Engineering and Technology Management, among others.

Barbara A. Ribbens (PhD, University of Connecticut) is Associate Professor of Management in the College of Business at Illinois State University, USA. Her research includes sustainability, careers, and decisionmaking issues in the global context. She has published in Career Development International, Academy of Management Journal, and Small Group Research, among others.

Terry W. Noel (PhD, University of Colorado at Boulder) is Associate Professor of Management and Quantitative Methods in the College of Business at Illinois State University, USA. He has published in the Academy of Management Journal, Journal of Small Business Management, Journal of Leadership and Organizational Studies, Journal of Business Ethics, Journal of Management Education, Journal of Entrepreneurship, and Journal of Entrepreneurship Education, among others.

Gurmeet Singh ( $\mathrm{PhD}$, University of Jammu) is Associate Professor of Management in the School of Management and Public Administration at the University of the South Pacific, Fiji. He has contributed more than 100 articles in leading international journals and conferences including recently in the Personality and Individual Differences, Public Organization Review, International Journal of Business and Economics, and International Journal of Public Administration, among others. 